\title{
Erratum to: Several Articles in Journal of Applied Mechanics and Technical Physics
}

DOI: $10.1134 / \mathrm{S} 0021894420070238$

In the copyright line of the following articles, the year of publication of Russian version should read 2018.

\section{Phenomenological Simulation of the Phase and Structural Deformation in Shape Memory Alloys. One-Dimensional Case}

\author{
K. A. Tikhomirova \\ Institute of Continuous Media Mechanics, Ural Branch, Russian Academy of Sciences, Perm, 614013 Russia \\ e-mail: tikhomirova.k@icmm.ru \\ Received December 11, 2017; revised January 24, 2018; accepted January 29, 2018
}

DOI: $10.1134 / \mathrm{S} 0021894419070125$

Journal of Applied Mechanics and Technical Physics, 2019, Vol. 60, No. 7, pp. 1149-1161. (C) Pleiades Publishing, Ltd., 2019.

Russian Text (C) The Author(s), 2018, published in Vychislitel'naya Mekhanika Sploshnykh Sred, 2018, Vol. 11, No. 1, pp. 36-50.

\section{Shear Banding of a Fluid Flow with a Nonmonotonic Dependence of the Flow Stress on the Strain Rate}

\author{
Yu. L. Kuznetsova ${ }^{a, *}$ and O. I. Skul'skiy ${ }^{a, * *}$ \\ ${ }^{a}$ Institute of Continuous Media Mechanics, Ural Branch, Russian Academy of Sciences, Perm, 614013 Russia \\ *e-mail:julyashmit@gmail.com \\ **e-mail: skul@icmm.ru
}

Received January 16, 2018; revised January 28, 2018; accepted February 5, 2018

DOI: $10.1134 / \mathrm{S} 002189441907006 \mathrm{X}$

Journal of Applied Mechanics and Technical Physics, 2019, Vol. 60, No. 7, pp. 1162-1174. (C Pleiades Publishing, Ltd., 2019.

Russian Text (C) The Author(s), 2018, published in Vychislitel'naya Mekhanika Sploshnykh Sred, 2018, Vol. 11, No. 1, pp. 68-78.

\section{Simulation of the Response of Microferrogel to External Magnetic Field}

\author{
A. V. Ryzhkov ${ }^{a, b, *}$ and Yu. L. Raikher ${ }^{a, b, * *}$ \\ a Institute of Continuous Media Mechanics, Ural Branch, Russian Academy of Sciences, Perm, 614013 Russia \\ ${ }^{b}$ Perm National Research Polytechnic University, Perm, 614990 Russia \\ *e-mail: ryzhkov.a@icmm.ru \\ **e-mail: raikher@icmm.ru \\ Received November 23, 2018; revised February 13, 2019; accepted February 19, 2019
}

DOI: $10.1134 / \mathrm{S} 0021894419070113$

Journal of Applied Mechanics and Technical Physics, 2019, Vol. 60, No. 7, pp. 1175-1183. (C Pleiades Publishing, Ltd., 2019. Russian Text (C) The Author(s), 2018, published in Vychislitel'naya Mekhanika Sploshnykh Sred, 2018, Vol. 11, No. 1, pp. $111-119$. 


\title{
Estimation of the Possibility to Equalize the Fluid Temperature in a Hydrolevelling System by Mixing
}

\author{
S. V. Lekomtsev ${ }^{a, *}$ and R. V. Tsvetkov ${ }^{a, * *}$ \\ ${ }^{a}$ Institute of Continuous Media Mechanics, Ural Branch, Russian Academy of Sciences, Perm, 614013 Russia \\ *e-mail: lekomtsev@icmm.ru \\ **e-mail:flower@icmm.ru
}

Received April 18, 2018; revised June 6, 2018; accepted June 7, 2018

DOI: $10.1134 / \mathrm{S} 0021894419070071$

Journal of Applied Mechanics and Technical Physics, 2019, Vol. 60, No. 7, pp. 1197-1208. (C Pleiades Publishing, Ltd., 2019. Russian Text (C) The Author(s), 2018, published in Vychislitel'naya Mekhanika Sploshnykh Sred, 2018, Vol. 11, No. 2, pp. $202-213$.

\section{Mathematical Modeling of Failure Process of AlMg2.5 Alloy in High and Very High Cycle Fatigue}

\author{
D. A. Bilalov ${ }^{a, *}$, Yu. V. Bayandin ${ }^{a, * *}$, and O. B. Naimark ${ }^{a, * * *}$ \\ ${ }^{a}$ Institute of Continuous Media Mechanics, Ural Branch, Russian Academy of Sciences, Perm, 614013 Russia \\ *e-mail:ledon@icmm.ru \\ **e-mail:buv@icmm.ru \\ ***e-mail: naimark@icmm.ru
}

Received September 13, 2018; revised September 26, 2018; accepted September 26, 2018

DOI: $10.1134 / \mathrm{S} 0021894419070022$

Journal of Applied Mechanics and Technical Physics, 2019, Vol. 60, No. 7, pp. 1209-1219. (C) Pleiades Publishing, Ltd., 2019.

Russian Text (C) The Author(s), 2018, published in Vychislitel'naya Mekhanika Sploshnykh Sred, 2018, Vol. 11, No. 3, pp. $323-334$.

\section{Influence of Hydrodynamic Regimes on Mixing of Waters of Confluent Rivers}

\section{T. P. Lyubimova ${ }^{a, b, *}$, A. P. Lepikhin ${ }^{b, c, * *}$, Ya. N. Parshakova ${ }^{a, * * *}$, C. Gualtieri ${ }^{d, * * * *}$, S. Lane Le $^{e * * * *}$, and B. Roux $f, * * * * * *$}

anstitute of Continuous Media Mechanics, Ural Branch, Russian Academy of Sciences, Perm, 614013, Russia

${ }^{b}$ Perm State University, Perm, 614990 Russia

${ }^{c}$ Mining Institute, Ural Branch, Russian Academy of Sciences, Perm, 614007 Russia

${ }^{d}$ University of Naples Federico II, Naples, Italy

${ }^{e}$ Institute of Earth Surface Dynamics, University of Lausanne, Lausanne, CH-1015 Switzerland

${ }^{f}$ Aix-Marseille Universitŭ and Ecole Centrale Marseille, Marseille, 13007 France

*e-mail: lyubimovat@mail.ru

**e-mail: lepihin49@mail.ru

***e-mail:parshakova@icmm.ru

****e-mail: carlo.gualtieri@unina.it

*****e-mail: stuart.lane@unil.ch

******e-mail: broux@L3M.univ-mrs.fr

Received September 4, 2018; revised October 10, 2018; accepted October 12, 2018

DOI: $10.1134 /$ S0021894419070083

Journal of Applied Mechanics and Technical Physics, 2019, Vol. 60, No. 7, pp. 1220-1227. (C Pleiades Publishing, Ltd., 2019. Russian Text (C) The Author(s), 2018, published in Vychislitel'naya Mekhanika Sploshnykh Sred, 2018, Vol. 11, No. 3, pp. 354-361. 


\title{
Secondary Convection Regimes in a Fluid with a Temperature-Dependent Viscosity in a Plane Vertical Layer
}

\author{
T. P. Lyubimova ${ }^{a, b, *}$ \\ ${ }^{a}$ Institute of Continuous Media Mechanics, Ural Branch, Russian Academy of Sciences, Perm, 614013 Russia \\ ${ }^{b}$ Perm State University, Perm, 614990 Russia \\ *e-mail: lubimova@psu.ru \\ Received August 2, 2018; revised October 6, 2018; accepted October 8, 2018
}

DOI: $10.1134 / \mathrm{S} 0021894419070095$

Journal of Applied Mechanics and Technical Physics, 2019, Vol. 60, No. 7, pp. 1228-1236. (C) Pleiades Publishing, Ltd., 2019. Russian Text (C) The Author(s), 2018, published in Vychislitel'naya Mekhanika Sploshnykh Sred, 2018, Vol. 11, No. 4, pp. $369-377$.

\section{Turbulent Convection of Liquid Sodium in an Inclined Cylinder of Unit Aspect Ratio}

\author{
S. D. Mandrykin ${ }^{a, *}$ and A. S. Teimurazov ${ }^{a, * *}$ \\ ${ }^{a}$ Institute of Continuous Media Mechanics, Ural Branch, Russian Academy of Sciences, Perm, 614013 Russia \\ *e-mail:msd@icmm.ru \\ **e-mail: tas@icmm.ru \\ Received October 11, 2018; revised November 2, 2018; accepted November 2, 2018
}

DOI: $10.1134 / \mathrm{S} 0021894419070101$

Journal of Applied Mechanics and Technical Physics, 2019, Vol. 60, No. 7, pp. 1237-1248. (C) Pleiades Publishing, Ltd., 2019. Russian Text (C) The Author(s), 2018, published in Vychislitel'naya Mekhanika Sploshnykh Sred, 2018, Vol. 11, No. 4, pp. 417-428.

\section{Analysis of the Spatial Vibrations of Coaxial Cylindrical Shells Partially Filled with a Fluid}

\author{
S. A. Bochkarev ${ }^{a, *}$, S. V. Lekomtsev ${ }^{a, * *}$, and A. N. Senin ${ }^{a, * * *}$ \\ ${ }^{a}$ Institute of Continuous Media Mechanics, Russian Academy of Sciences, Ural Branch, Perm, 614013 Russia \\ *e-mail: bochkarev@icmm.ru \\ **e-mail:lekomtsev@icmm.ru \\ ***e-mail: senin.a@icmm.ru
}

Received November 12, 2018; revised December 3, 2018; accepted December 5, 2018

DOI: $10.1134 / \mathrm{S} 0021894419070046$

Journal of Applied Mechanics and Technical Physics, 2019, Vol. 60, No. 7, pp. 1249-1263. (C) Pleiades Publishing, Ltd., 2019. Russian Text (C) The Author(s), 2018, published in Vychislitel'naya Mekhanika Sploshnykh Sred, 2018, Vol. 11, No. 4, pp. $448-462$.

\section{Modeling of the Marangoni Instability of Uniform Diffusion through an Interface in Weightlessness Conditions}

\author{
R. V. Birikh ${ }^{a, *}$, M. O. Denisova ${ }^{a, * *}$, and K. G. Kostarev ${ }^{a, * * *}$ \\ ${ }^{a}$ Institute of Continuous Media Mechanics, Ural Branch, Russian Academy of Sciences, \\ Perm, 614013 Russia \\ *e-mail: rbirikh@mail.ru \\ **e-mail:mod@icmm.ru \\ ***e-mail: kostarev@icmm.ru
}

Received October 23, 2018; revised December 14, 2018; accepted December 18, 2018

DOI: $10.1134 / \mathrm{S} 0021894419070034$

Journal of Applied Mechanics and Technical Physics, 2019, Vol. 60, No. 7, pp. 1264-1277. (C Pleiades Publishing, Ltd., 2019. Russian Text (C) The Author(s), 2018, published in Vychislitel'naya Mekhanika Sploshnykh Sred, 2018, Vol. 11, No. 4, pp. 463-475.

JOURNAL OF APPLIED MECHANICS AND TECHNICAL PHYSICS $\quad$ Vol. $61 \quad$ No. $7 \quad 2020$ 